\title{
THE ROLE OF THE METONIMICAL TRANSFER IN THE FORMATION OF EXPRESSIONS RELATED TO THE CONCEPT OF «DEATH" IN RUSSIAN AND PERSIAN LANGUAGES
}

\author{
Mohanna KH. Seyed Agaie Rezaie \\ University of Mazandaran, Islamic Republic of Iran, Mazandaran, \\ 47416-13534, Babolsar, Pasdoran str.
}

\begin{abstract}
This study analyses the role of metonymic transfer in the formation of euphemisms in the semantic field of "death" in Russian and Persian languages. Death as an inevitable reality in human's life possesses an important place in all languages and cultures. Dealing with this concept has been always difficult. The word "death" invokes fear and discomfort among people. Sometimes fear, and sometimes a sense of politeness and decency make people take advantage of euphemisms. Metonymic transfer is one of the most relevant ways to form euphemisms in the semantic field of "death".

Metonymy refers to the transfer of titles from one subject to another based on proximity. In line with metonymy, different kinds of it including synecdoche and metalepsis in Russian and implicature and allegory in Persian also play important roles in the formation of euphemisms of the "death" concept. In this article, we would categorize the Russian as well as Persian euphemisms, which are formed on the basis of metonymic transfer, into three groups: 1) euphemistic units, formed by means of metonymy; 2) euphemistic units formed by metalepsis; 3) euphemistic units formed by synecdoche. While comparing Russian and Persian euphemisms in the semantic field of "death", we aim to clarify the similarities and differences of the usage of metonymic transfer in these two languages.
\end{abstract}

Key Words: euphemism, metonymic transfer, metalepsis, synecdoche, death, Russian, Persian

For citation: Mohanna KH. Seyed Agaie Rezaie, 2021. The Role of the Metonimical Transfer in the Formation of Expressions Related to the Concept of "Death" in Russian and Persian Languages. Philological Sciences at MGIMO.Vol. 7. No 1(25). P. 148-155. https://doi.org/10.24833/2410-24232021-1-25-149-155 


\title{
РОЛЬ МЕТОНИМИЧЕСКОГО ПЕРЕНОСА В ОБРАЗОВАНИИ ВЫРАЖЕНИЙ, СВЯЗАННЫХ С ПОНЯТИЕМ "СМЕРТЬ": НА МАТЕРИАЛЕ РУССКОГО И ПЕРСИДСКОГО ЯЗЫКОВ
}

\author{
M.Х. Сейед Агаи Резаи \\ Мазандаранский университет, \\ Иран, Мазандаран, 47416-13534, г. Бабольсар, ул. Пасдаран
}

\begin{abstract}
Аннотация. Данное исследование посвящено анализу роли метонимического переноса в образовании эвфемизмов в семантическом поле «смерть» на материале русского и персидского языков. Смерть как неизбежная реальность занимает особое место во всех языках и культурах мира. Говорить о смерти всегда бывает трудно. Слово «смерть» вызыьвает страх среди людей. Иногда страх, а иногда чувство вежливости и приличия служат причиной появления эвфемизмов, связанных с этим понятием. Метонимический перенос считается одним из наиболее актуальных способов образования эвфемизмов в семантическом поле «смерть».

Под метонимией понимается перенос наименований с одного предмета на другой по смежности. Наряду с метонимией её разновидности, синекдоха, металепсис в русском языке и в كنايه (= иносказательность) в персидском, тоже играют важную роль в образовании эвфемизмов концепта «смерть». В нашей работе мы распределяем русские и персидские эвфемизмы, образованные на основе метонимического переноса, по трём группам: 1) эвфемистические единицы, образованные с помощью метонимии; 2) эвфемистические единицы, образованные с помощью металепсиса; 3) эвфемистические единицы, образованные с помощью синекдохи. При сопоставлении русских и персидских эвфемизмов нами определяются черты сходства и различия в использовании метонимического переноса в этих двух языках.
\end{abstract}

Ключевые слова: эвфемизм, метонимический перенос, металепсис, синекдоха, смерть, русский языкк, персидский язык

Для цитирования: М.Х. Сейед Агаи Резаи, 2021. Роль метонимического переноса в образовании выражений, связанных с понятием «смерть»: на материале русского и персидского языков. Филологические науки в МГИМО. Том 7. № 1(25). С. 148-155. https://doi.org/10.24833/2410-24232021-1-25-148-155

Ч еловеку невозможно перестать думать о смерти. Она считается неотъемлемой частью жизни каждого существа, но до сих пор никто не смог раскрыть таинственные черты этого непреложного явления. Поэтому смерть как неизвестная реальность вызывает бесконечный страх и волнение. Из истории известно, что смерть для человека всегда страшна, значима, таинственна и неотвратима. Жизнь человечества - настоящая трагедия, ибо она кончается смертью. Люди по-разному относятся к смерти: некоторые считают её концом жизни и началом небытия и гибели. Другие полагают, что смерть подобна новому рождению. Так, для того чтобы уменьшить страх смерти, человек старается прибегать к духовности и религии. По исламским верованиям смерть является началом следующей ступени жизни, и, согласно иранской мистике, она считается возвращением к сути, к Богу, с земли на небо. По мнению религиозных мыслителей, религия 
защищает людей в тяжёлых ситуациях, помогает, когда они оказываются в безвыходном положении. Язык как орудие мышления и познания также может помогать человечеству спасаться в таких естественных тупиковых ситуациях. В общественной жизни мы часто избегаем говорить прямо о смерти и смертельных болезнях. Тогда мы начинаем широко использовать такое языковое средство, как метонимический перенос.

Языковое табу выражается в запрете на прямое наименование неприятного явления, и оно лежит в основе эвфемизации. Так, первые эвфемизмы появились в ответ на языковые запреты или табу, и можно сказать, что эвфемизм и табу - две стороны одной и той же монеты. Под эвфемизмом принято понимать «лексические единицы или выражения, используемые для замены такого прямого наименования, употребление которого представляется говорящим неуместным в данной конкретной ситуации» [5, с. 6]. С древнейших времён смерть как неизбежная часть жизни каждого существа находится под языковым запретом во всех языках и культурах мира, и для создания эвфемизмов, употребляемых взамен этого табуируемого понятия, используются разные лексико-семантические, стилистические, морфологические, фонетические, графические способы и приёмы. В данном исследовании нами рассматривается один из наиболее продуктивных способов эвфемизации, то есть метонимический перенос, и указывается на существующие различия и сходство при использовании этого способа в русском и персидском языках.

Русские и иранские исследователи однозначно подчёркивают важность метонимии в эвфемистическом переименовании. Важность данного способа эвфемизации подчёркивалась такими русскими лингвистами, как В.П. Москвин, А.М. Кацев, Б.В. Томашевский [5, с. 30; 2, с. 18; 10, c. 56] и др. Для обозначения данного способа эвфемизации исследователи используют различные термины: метонимизация, метонимическая номинация, метонимический перенос.

Метонимия - перенос наименований с одного предмета на другой по смежности. Она основана на близкой и легко понимаемой смежности, сопредельности в пространстве или во времени, вовлечённости в одну ситуацию обозначаемых реалий, лиц, действий, процессов и т.п. [3, с. 55]. Одним из своеобразных видов метонимии является синекдоха. Синекдоха - это такой перенос значения, когда название части употребляется в значении целого, меньшего - в значении большего и наоборот [1, с. 128]. Под метонимией мы вслед за В.П. Москвиным понимаем также и её разновидность - металепсис. Металепсис представляет собой обозначение одной ситуации или явления через другие, так или иначе с ними связанные. Посредством металепсиса ситуацию можно обозначить: 1) по предшествующему действию: взяться за оружие в значении «начать войну»; 2) по сопутствующему действию: махать косой в значении «косить»; 3) по результату: преломить копья с кем-л. вместо «сразиться» [4, с. 161].

По определению иранского лингвиста М. Мирсадеги, метонимией (= مجاورت [mojāverat]) является вид тропа, основанный на смежности. Автор отмечает, что в тропе должна существовать какая-то связь междупрямым и переносным значением, чтобы слушатель или читатель смог в своём уме найти связь между словом и заменяемым понятием. Эта связь в персидском языке называется «علاقها" [alāqe]. У метонимии число и виды связей (علاقه) не ограничены. Но традиционно вы-

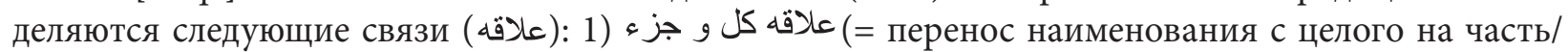

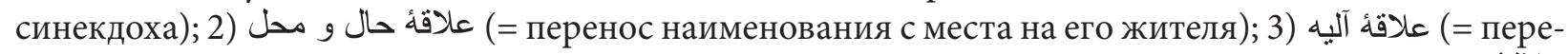

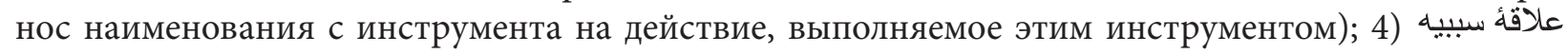
(= перенос наименования с причины какого-то явления на само явление) и др. [14, с. 231].

Можно перечислять и другие эквиваленты термина «метонимия» в персидском языке - «جاز / دكرنامى / كنايه آورى [majāz/ kenāye-āvari/ degar-nāmi]. С. Дад полагает, что определение термина «metonymy» (=метонимия) в английском языке совершенно совпадает с определением другого вида тропа - «كنايها" [kenāye] (= иносказательность) в персидском [12, с. 429].

Необходимо упомянуть, что точный эквивалент термина «كنايه" [kenāye] в русском языке отсутствует. По определению некоторых иранских исследователей, этот термин в некоторой степени похож на антонамасию: «В европейской литературе термин antonomasia по значению близок к понятию كنايه [kenāye] в персидском языке» [14, с. 221]. Другие лингвисты считают كنايه [kenāye] частью метонимии [13, с. 85]. Отличие كنايه [kenāye] от метонимии состоит в том, что адресат мо- 
жет иметь в ввиду и первичное и вторичное значение выражения, образованного на основе كنايه [kenāye], но в метонимии важным считается только вторичное, переносное значение. В связи с тем, что этот вид тропа не имеет аналогичный эквивалент в русском языке, мы называем его метонимией в нашей работе.

Таким образом, понятия метонимии в русском и персидском языках в общем совпадают, но существуют некоторые отличия в выделении её разновидностей. Синекдоха считается разновидностью метонимии и в персидском языке. Металепсис как разновидность метонимии не существует в персидском языке, но отчасти может совпадать с другим лексическим термином - استلز ام معنايى (англ. implication, pус. импликатура). استلز ام كعنايى (импликатура) - это семантическая связь между двумя предложениями, под которой понятие предложения «Х» зависит от понятия предложения «Y», или, иными словами: когда «Х» действителен, то «Ү» тоже будет действителен. Например:

$$
\text { بدربزرگ در اين اتاق نفس آخر را كثيد. }
$$

Дедушка испустил последний вздох (похожий вариант в русском языке - «чуть (еле) дышать»). Это предложение образовано на основе «إستلز ام معنايى (= импликатуры). Говорящий косвенно выражает, что если дедушка испустил последний вздох, то он уже умер. Иными словами, информация присутствует в тексте в скрытом виде, и адресат сам делает вывод [15, с. 83]. По нашему мнению, можно считать استلز ام معنايى (импликатуру) разновидностью метонимии, и этот лингвистический термин даже в некоторой степени похож на металепсис.

Как указано выше, метонимия и её разновидности широко используются при образовании эвфемизмов концепта «смерть» и в русском и в персидском языках. Использование метонимии и ее разновидностей как распространённого способа эвфемистической замены связано с тем, что, называя «смежный» предмет или явление, номинант тем самым избегает табуируемого прямого наименования, а отношение смежности позволяет собеседнику соотнести два понятия и правильно «расшифровать» эвфемизм [7, с. 56].

Далее рассматриваются некоторые метонимические эвфемизмы в семантическом поле «смерть», функционирующие во всех стилях (нейтральном, возвышенном и низком) русского и персидского языков, и анализируются сходства и различия при их образовании. В ходе нашей работы нами распределяются русские и персидские эвфемизмы, образованные на основе метонимического переноса, по трём группам: 1. эвфемистические единицы, образованные с помощью метонимии; 2. эвфемистические единицы, образованные с помощью металепсиса; 3. эвфемистические единицы, образованные с помощью синекдохи. Материалом для исследования послужили слова, выражения и предложения, выбранные из словарей русского и персидского языков. Для сбора примеров в русском языке нами использованы «Словарь эвфемизмов русского языка» Е.П. Сеничкиной [8], а для сбора и анализа слов и выражений, выступающих в функции эвфемизма в персидском языке, использовали «Большой словарь Сохан» Х. Анвари [11].

А. Эвфемистические единицы, образованные с помощью метонимии:

1) «Гроб» и «гробовая дверь/ гробовые двери» вместо «смерть»; «за гробом», «за дверью гроба» вместо «после смерти». В этих эвфемизмах мы сталкиваемся с переносом наименования с места (гроб) на явление (смерть).

2) «Два метра» вместо «могила». Это выражение зафиксировано как эвфемизм во второй половине XX века и обладает ироническим характером. Образование этого метонимического переноса восходит к похоронному обряду в России, согласно которому покойников хоронят именно на двухметровой глубине.

$3)$ «Одр» вместо «смерть» (употребляется в книжной речи). Это слово в прямом значении обозначает «постель, ложе умирающего», но в переносном значении служит эвфемизмом, образованным за счёт переноса наименования смежного состояния.

4) «Свет из очей выкатится», «очи в гору пойдут», «вытянуть ножки», «протянуть ноги», «закрыть глаза», «смежить очи», «сложить руки» и др. вместо «умирать». Данные метонимические конструкции косвенно указывают на смерть с помощью признаков этого явления.

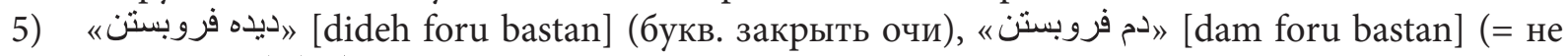

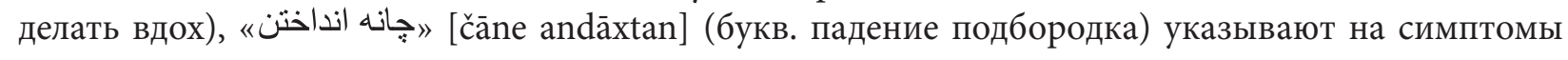


умершего, когда он теряет такие основные жизненные признаки, как зрение, дыхание, говорение и т.п.

6) " [بوى حلو اى كسى بلند شدن [buy-e halvay-e kasi boland šodan] (букв. распространяется запах

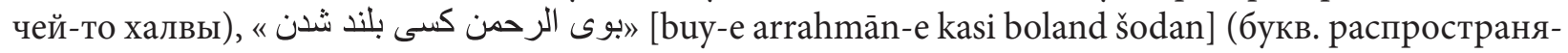
ется запах Ар-рахмана) в значении «дышать на ладан/ быть одной ногой в могиле». По исламским традициям в траурных собраниях гостей угощают халвой, чтец Корана читает суру Ар-Рахмана (55-ой суры Корана с 88 аятами). Так, очевидно, данные метонимические конструкции связаны с обозначением смерти по действиям, соотносящимся с исламским похоронным обрядом.

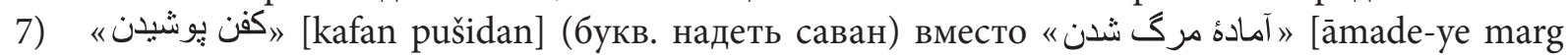
šodan] (букв. готовиться к смерти). Этот эвфемизм связан непрямо со смертью по действиям, соотносящимся с мусульманским похоронным обрядом.

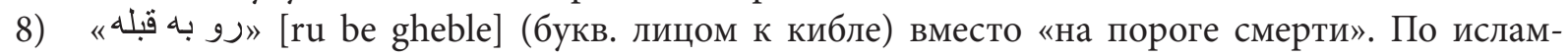
ским наставлениям, находящегося в агонии человека располагают в сторону киблы, или умершего мусульманина кладут в могилу на правый бок лицом к кибле. Этот метонимический эвфемизм связан с обозначением смерти по действиям, соотносящимся с исламским похоронным обрядом.

9) «كرباس» [karbās] (букв. холст) выполняет эвфемистическую функцию взамен прямого

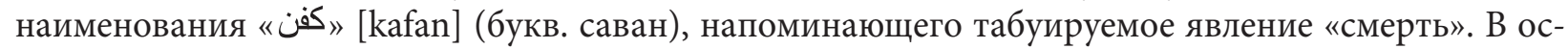
нове этого эвфемизма лежит приём метонимического переноса - переноса названия вещества, материала, на изделие из него.

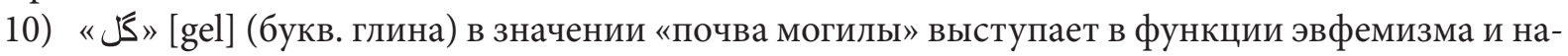
мекает на табуируемое понятие «смерть». Напр.:

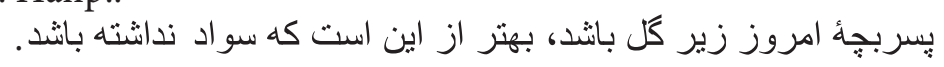

В сегоднямние дни лучше быть под глиной (вместо «умереть»), чем быть безграмотным.

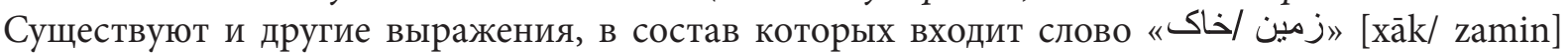
(букв. почва/ земля) в метонимическом переносном значении, выполняющие эвфемистическую

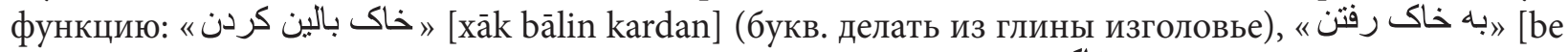

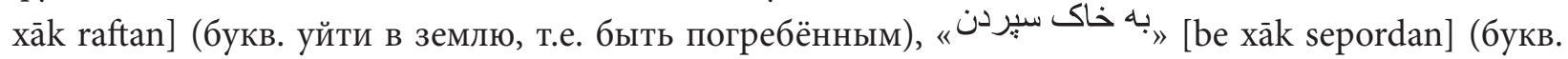
предавать земле) «ور نقاب خاك كثيدن روى (ruy dar neqāb-e xāk kešidan] (закрывать лицо глиняным

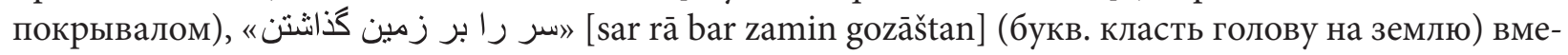
сто «умирать», «быть погребённым», «скончаться» и т.п.

11) "بر مركب جوبين نشستن "bar markab-e čubin nešatan] (букв. сидеть на деревянном верховом животном) иносказательно указывает на понятие «смерть» и выполняет эвфемистическую функцию. При образовании этого эвфемизма параллельно действуют два способа эвфемизации - метафорический и метонимический перенос. Деревянное верховое животное в метафорическом значении - это то же, что гроб, и сидеть на гробе метонимически употреблено в значении умирать, то есть наблюдается перенос наименования по смежности.

12) Великий персидский поэт Фирдоуси в этом стихе использует метонимию, чтобы прямо

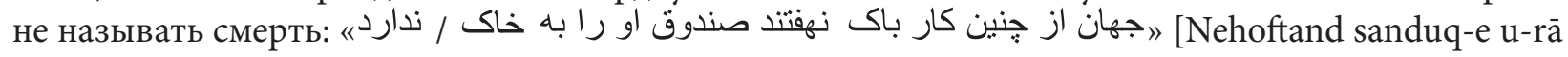
be xāk/ nadārad jahān az čenin kār bāk] (схоронили они сундук его в землю/ нет миру от этого дела страха). В этом примере слово «сундук» употребляется в переносном значении «гроб». Хоронят умерших в гробу. Здесь происходит перенос наименования с вместилища на содержимое.

13) В некоторых аятах священного Корана вместо прямого обозначения смерти употребляется метонимия "مأمور" [mamur] (исполнитель) и قاضى" [qazi] (судья). По исламским верованиям, по приказу Аллаха Маляк аль-маут (ангел смерти) забирает души умерших. Он помогает людям перейти в иной мир. В воображении мусульман Азраил - грозный и страшный. Здесь вместо прямого наименования «Азраил» употребляется наименование «исполнитель» и «судья». В персидской культуре эти профессии напоминали черты Ангела смерти. Здесь наблюдается перенос наименовании с действующего лица на само действие.

Б. Эвфемистические единицы, образованные с помощью металепсиса: 
1) «На ладан дышать» вместо «быть при смерти». Ладан - это жёлтоватая или красноватая ароматическая смола, употребляемая для курения при религиозных обрядах [6, с. 318]. В этом выражении вместо того, чтобы прямо говорить о смерти, обозначается ситуация по предшествующему действию.

2) «Глядеть в гроб/ в могилу», «одной ногой в могиле (стоять)» вместо «быть близким к смерти» образуются путём металепсиса, поскольку заключается в замене предшествующего (гроб) последующим (смерть).

3) «Чуть (еле) дышать» вместо «находиться при смерти». В этом случае эвфемистическим представляется обозначение ситуации по предшествующему действию, поскольку смерть человека связана с остановкой дыхания.

4) «Ложиться на стол», «ложиться в землю (в гроб)» вместо «умирать».

5) «На санях сидя» в значении «готовясь к смерти». Это выражение зафиксировано как эвфемизм в XI веке и восходит к архаической особенности: покойника на кладбище везли на санях.

6) «Приказать долго жить» вместо «умереть». В анализируемом случае - это отношение сопровождения: умирая, человек приказал (завещал другим, оставшимся) долго жить. По мере расширения сферы употребления этого фразеологизма его начинают применять в отношении не только человека, но и животного. Напр.: Здоров ти ваш медведь, батюшка Кирила Петрович, - сказал Антон Пафнутьич.. - Миша приказал долго жить, - отвечал Кирила Петрович (А.С. Пушкин. Дубровский). Очевидно, что, умирая, медведь никак не может пожелать людям долго жить. Семантическое выветривание фразеологизма приводит к тому, что сочетание начинают употреблять в значении «прекратить существование» [9, с. 29].

7) Образный перифраз «накормить рыб» выступает в функции языкового эвфемизма вместо «утонуть».

8) «Низринуться в прах», «становиться тленом» вместо «умирать». Слова «прах» и «тлен» указывают на ситуацию человека после смерти и, таким образом, косвенно называют явление смерти.

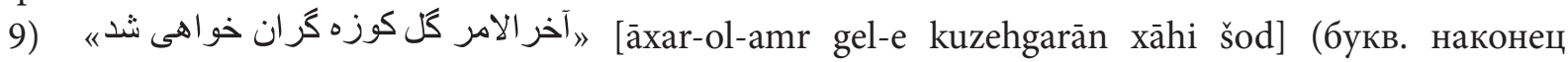
превратишься в горшечную глину) -первая мисра газели известного персидского поэта Хафиза. С течением времени она приобрела узуальный характер и вошла в словарный запас персоговорящих как крылатая фраза, употребляемая эвфемистически взамен прямого указания на смерть. В образовании этого эвфемизма действует استلز ام معنايى (= импликатура) или её русский эквивалент - металепсис, состоящий в обозначении одной ситуации через другие, так или иначе с ними связанные по результату: сначала человек умирает, потом его тело превращается в глину, наконец, гончары делают кувшины из этой глины.

10) عمر خود را به كسى دادن" [omr-e xod rā be kasi dādan] (букв. дать свою жизнь другому) вм. «умирать». В этом примере наблюдается перенос наименования с одной ситуации на другую, и можно считать его точным эквивалентом эвфемистического фразеологизма приказать кому-л. долго жить, образованным тем же способом в русском языке.

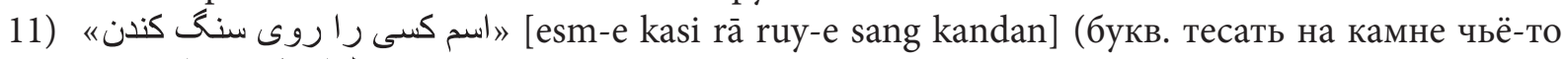
имя), « حلو ایى كسى را خوردن" [halvāye kasi rā xordan] (букв. есть чью-то халву) вместо «умирать». Это эвфемизмы, образованные на основе металепсиса или его персидского эквивалента استلز ام معنايى (импликатуры), поскольку сначала человек умирает, потом на его могильном камне тешут его имя и угощают гостей халвой в день по случаю траура.

12) В иранской мистике металепсисы употребляются для того, чтобы косвенно указывать на смерть: «بازكثت به اصل " بbāzgašt be asl] (возвращение к происхождению), возвращение к Богу -

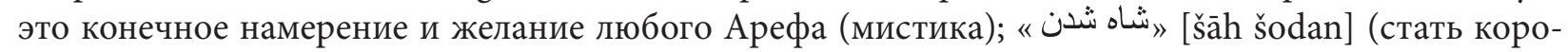
лём) человек на земле живёт как бедняк, но со смертью превращается в короля; “شј» [zāyeš] (рождение) - смерть считается другим рождением; «غلوغ [blooq] (зрелость) - смерть переведёт человека с одного этапа жизни на другой; « اكسير » [eksir] (эликсир) - смерть действует, как эликсир, она превращает человеческое тело в драгоценную субстанцию. Как видим, по мистическим верованиям смерть описывается положительно. Таким образом, фразеологизмы указывают на 
ситуацию человека после смерти, и это приводит к тому, что люди положительно относятся к страшному явлению.

В. Эвфемистические единицы, образованные с помощью синекдохи:

1) 《دست كسى از دنيا كوتناه شدن "دdast-e kasi az donyā kutāh šodan] (букв. чья-то рука укорачивается из этого мира) намекает на понятие «смерть». В этом эвфемистическом фразеологизме применяется приём синекдохи, состоящей в употреблении названия части (рука) для обозначения целого (человек).

2) «فاتحه " [fātehe] (букв. Фатиха, первая сура Корана) вместо «траурное собрание». По исламским традициям на траурных церемониях читают Фатиху, первую суру Священного Корана, как молитву по умершему. Чтение молитвы по усопшему считается частью мусульманской траурной церемонии, но в этом примере чтение суры «Фатиха» как части этой церемонии используется взамен прямого указания на саму траурную церемонию. Так, в основе этого эвфемизма лежит синекдоха.

Выполненное сопоставительное исследование позволяет сделать вывод, что метонимический перенос считается одним из наиболее продуктивных способов образования эвфемизмов концепта «смерть» в русском и персидском языках. Необходимо упомянуть, что существуют некоторые различия при определении и классификации метонимии в персидском языке, поскольку различаются мировоззрение и совокупность убеждений носителей этих языков. В персидском языке есть

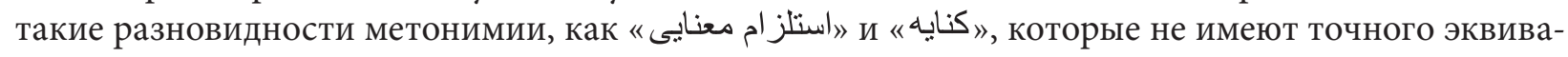
лента в русском языке. Наиболее близкий эквивалент первого в русском языке - «металепсис», а для второго, в некоторой степени, - «метонимия» и «антономазия».

В ходе нашей работы мы распределили русские и персидские эвфемизмы, образованные на основе метонимического переноса, по трём группам. Согласно нашему исследованию, при образовании эвфемизмов семантического поля «смерть» чаще употребляются: 1) смежность в пространстве; 2) материал - изделие; 3) субъект действия - место действия. При образовании эвфемизмов первого разряда тоже указываются либо симптомы, сопровождающие смерть, либо действия, соотносящиеся с похоронным обрядом. Эвфемизмы второго разряда образованы на основе металепсиса. Поскольку в персидском языке не существует точного эквивалента этого понятия, мы включили в этот разряд примеры из персидского языка, образованные с помощью معنايى استلز ام (импликатура). В третий разряд входят фразеологизмы, образованные синекдохой. Как видим, синекдоха как разновидность метонимии не является продуктивным способом образования эвфемизмов концепта «смерть» в русском, в отличие от персидского языка.

(C) Сейед Агаи Резаи M.X., 2021

\section{Список литературы}

1. Гируцкий А. А. Введение в языкознание: Учеб. пособие. 2-ое изд., стер. Мн.: ТетраСистемс, 2003. 288 с.

2. Кацев А. М. Языковое табу и эвфемия: учеб. пособие к спецкурсу. Л.: ЛГПИ им. А. И. Герцена, 1988.80 с.

3. Крысин Л. П. Современный русский язык. Лексическая семантика. Лексикология. Фразеология. Лексикография: учеб. пособие для студ. филол. фак. высш. учеб. заведений/ М.: Издательский центр Академия, 2007. 240 с.

4. Москвин В. Н. Способы эвфемистической зашифровки в современном русском языке // Языковая личность: социолингвистические и эмотивные аспекты. Волгоград; Саратов, 1998. С. 160-167.

5. Москвин В.П. Эвфемизмы в лексической системе современного русского языка. М.: ЛЕНАНД, 2007. 264 с.

6. Ожегов С. И. Толковый словарь русского языка: 80000 слов и фразеологических выражений /С.И. Ожегов, Н.Ю. Шведова / Российская академия наук. Институт русского языка им. В. В. Виноградова. 4-е изд., дополненное. М.: Азбуковник, 1999. 944 с.

7. Прудывус А. Н. Эвфемизмы в современном немецком языке: диссертация на соискание учёной степени кандидата филологических наук. Санкт-Петербург. 2006. 188 с.

8. Сеничкина Е. П. Словарь эвфемизмов русского языка. М.: Флинта: Наука, 2008. 461 с.

9. Сеничкина Е.П. Эвфемизмы русского языка. М.: Флинта, 2012.120 с.

10. Томашевский Б. П. Теория литературы. Поэтика. Л.: Гос. изд., 1928. 334 с. 


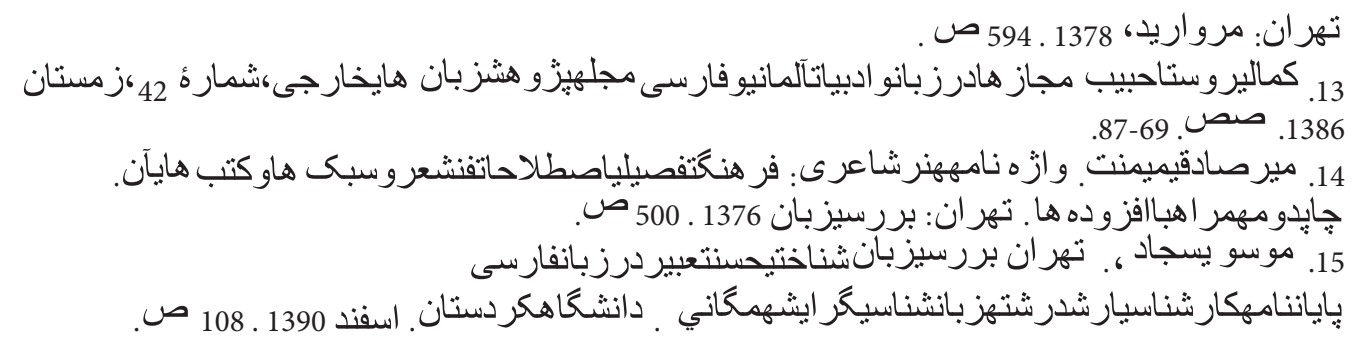

\section{References}

1. Girutskiy, A. A. Vvedenie viazykoznanie: Ucheb. Posobie [Introduction to Linguistics: Tutorial]. 2-oe izd., ster. Mn.: TetraSistems, 2003. 288 p.

2. Katsev, A. M. Iazykovoe tabu i evfemiia: ucheb. posobie k spetskursu [Language taboo and euphemia: studies. manual for special course. L.]. L.: LGPI im. A. I. Gercena, 1988. 80 p.

3. Krysin, L. P. Sovremenny russkii iazyk. Leksicheskaia semantika. Leksikologiia. Frazeologiia. Leksikografiia: ucheb. posobie dlia stud. filol. fak. vyssh. ucheb. Zavedenii [Modern Russian. Lexical semantics. Lexicology. Phraseology. Lexicography: studies. A manual for stud. filol. fact higher studies. institutions]/ M.: Izdatel'skii tsentr Akademiia, 2007. 240 p.

4. Moskvin, V.N. Sposobi evfemisticheskoy zashifrofki v sovremennom russkom iazyke [Methods of euphemistic coding in modern Russian] // Linguistic personality: sociolinguistic and emotive aspects [Russian Academy of Sciences. Institute of Russian Language]. Volgograd; Saratov, 1998. 161 p.

5. Moskvin, V.P. Evfemizmy v leksicheskoi sisteme sovremennogo russkogo iazyka [Euphemisms in the lexical system of the modern Russian language]. Izd. 2-e. M.: LENAND, 2007. 264 p.

6. Ozhegov, S. I., Shvedova, N. Ju. Tolkovy slovar' russkogo iazyka: 80000 slov i frazeologicheskikh vyrazhenii [The Explanatory Dictionary of the Russian Language: 80,000 words and phraseological expressions]/ Rossiiskaia akademiia nauk. Institut russkogo iazyka im. V. V. Vinogradova. 4-e izd., dopolnennoe. M.: Azbukovnik, 1999. 944 p.

7. Prudivus, A.N. Evfemizmy v sovremennom nemetskom iazyke [Euphemisms in modern German language] / dissertation for the degree of Candidate of Philology. St. Petersburg. 2006. 188 p.

8. Senichkina, E.P. Slovar evfemizmov russkogo iazyka [Dictionary of euphemisms of the Russian language]. M.: Flint: Science, 2008. $464 \mathrm{p}$.

9. Senichkina, E.P. Evfemizmy russkogo iazyka/ spetskurs [Euphemisms of the Russian language / special course]. M.: Flinta. 2012. $121 \mathrm{p}$.

10. Tomashevskii, B. P. Teoriia literatury. Poetika [Literature Theory. Poetics]. L.: Gos. izd., 1928. 334 p.

11. Anvari, Hasan. Farhang bozorg sokhan [The Great Culture of Speech]. Tehran: Sokhan, 1381.

12. Dad Sima. Farhang estelahat adabi: vaje name mafahim va estelahate adabi farsi va orupai be shive tatbighi va tozihi [Dictionary of literary terms: Glossary of Persian and European literary concepts and terms in a comparative and explanatory way]. Tehran: Pearl, 1378. 594 p.

13. Kamali rusta Habib. Majazha dar zaban va adabiyat almani [Permissions in German and Persian language and literature]. Majale pajoheshhaye khareji [Journal of Foreign Languages Research], Vol. 42, Winter 2007. P. 69-87.

14. Mirsadeghi meymanat. Vaje name honare shaeri: farhange tafzili estelahate fan sher va sabkha va kotobhaye an [Art Glossary: A Detailed Culture of the Terms of the Poetry and its Styles and Books]. Second Edition with add-ons. Tehran: Book Mahnaz, 1376. 500 p.

15. Mousavi, S. Barresi zabanshenakhti-e hosne tabir dar zabane farsi [Linguistic Study euphemism in Persian], Master's thesis in linguistics, Kurdistan University, 1391 (2012).

\section{Сведения об авторах:}

Сейед Агаи РезаиМоханна Хасан - кандидат филологических наук, ассистент профессора, преподаватель кафедры русского языка факультета гуманитарных и социальных наук Мазандаранского университета в Исламской республике Иран (Исламская республика Иран, Мазандаран, Балбльсар). Сфера научных и профессиональных интересов: лингвистика, семантика, лексикология, художественныйперевод. E-mail: m.rezaie@umz.ac.ir

\section{About the author:}

Seyed Agai Rezai Mohanna Khasan - PhD, Assistant Professor, Department of the Russian Language, Faculty of Humanities and Social Sciences, University of Mazandaran (Islamic Republic of Iran, Mazandaran, Babolsar). Spheres of research and professional interest: linguistics, semantics, lexicology, literary translation.

E-mail: m.rezaie@umz.ac.ir 